\title{
Expanded Endoscopic Endonasal Transtuberculum / Transplanum Approach to the Suprasellar Area: A Stepwise Approach
}

\section{Abordagem via endoscópica expandida transtuberculum - transplanum para a região supraselar: os passos da abordagem}

Rodrigo Alves de Carvalho Cavalcante 1,2,6 Rômulo Alberto Silva Marques²

Vinícius Gonçalves dos Santos ${ }^{3}$ Renato Mariano Nunes ${ }^{4}$ Tiago Fernando Scopel ${ }^{5,6}$ Vladimir Arruda Zaccariotti ${ }^{2}$ João Batista Arruda ${ }^{2}$ Yvens Barbosa Fernandes ${ }^{1}$

${ }^{1}$ Department of Neurology, Universidade Estadual de Campinas (UNICAMP), Campinas, SP, Brazil

2 Department of Neuro-Oncology, Hospital Araújo Jorge, Goiânia, Goiás, Brazil

${ }^{3}$ Department of Neurosurgery, Hospital Universitário Alzira Velano, Alfenas, MG, Brazil

${ }^{4}$ Department of Otorhinolaryngology, Hospital Otorrino de Goiânia, Goiânia, Goiás, Brazil

${ }^{5}$ Department of Otorhinolaryngology, Hospital das Clínicas, Universidade Federal do Mato Grosso do Sul, Campo Grande, MS, Brazil

6 Endoscopic Skull Base Anatomy, Research Fellows - 2011, University of Pittsburgh, PA, United States

Arq Bras Neurocir 2016;35:128-134.
Address for correspondence Vinícius Gonçalves dos Santos, MR, Department of Neurosurgery, Hospital Universitário Alzira Velano, Alfenas, MG, Brazil (e-mail: alfenasvinicius@yahoo.com.br; drigocavalcante@yahoo.com.br).
Abstract Keywords
- anatomy
- skull base
- sella turcica
- sphenoid sinus
- endoscope
- nasal

\section{Resumo \\ Palavras-Chave \\ - anatomia \\ - base do crânio \\ - sela Túrcica \\ - seio Esfenoidal \\ - endoscópio \\ - nasal}

The Expanded Endoscopic Endonasal Transtuberculum / Transplanum (EEETT) approach emerged as an amenable option to remove midline lesions, such as giant pituitary tumors, craniopharyngiomas, and tuberculum sellae meningiomas. Herein, the author's aim is to show a stepwise approach to the suprasellar area by EEETT and a case illustration.

A abordagem endoscópica endonasal expandida (AEEE) trans- tubérculo/ trans-plano têm se mostrado uma opção favorável para lesões da linha média para lateral, como tumores da hipófise, craniofaringiomas gigantes e meningiomas selares. $\mathrm{O}$ objetivo do autor é demonstrar os passos desta abordagem para a região suprasellar, por AEEE e um caso de ilustração. received

October 30, 2015

accepted

January 11, 2016

published online

March 14, 2016
DOI http://dx.doi.org/

10.1055/s-0036-1579755. ISSN 0103-5355.
Copyright $(2016$ by Thieme Publicações License terms

Ltda, Rio de Janeiro, Brazil (c) $(1) \$$ 


\section{Introduction}

Since the "expanded endoscopic endonasal approaches" have been popularized by Kassam et al over the last decade, lesions located in the suprasellar infrachiasmatic have been given another safe option for resection, obviating a brain retraction, an optic apparatus damage, and maximizing oncological resection for selected midline lesions. The Expanded Endoscopic Endonasal Transtuberculum / Transplanum (EEETT) approach emerged as an amenable option to remove midline lesions like giant pituitary tumors, craniopharyngiomas, and tuberculum sellae meningiomas. ${ }^{1-3}$ Even if the cerebral spinal fluid leak (CSF) is considered when utilizing this procedure, ${ }^{4}$ modern skull base reconstruction techniques are available to minimize this kind of complication. ${ }^{5}$ Herein, the author's aim is to show a stepwise approach to the Supra-Infrachiasmatic suprasellar area by EEETT and a case illustration.

\section{Materials and Methods}

We dissected and prepared four fixed and injected heads at the Surgical Neuroanatomy Laboratory of the Department of Neurological Surgery at the University of Pittsburgh. We cannulated the carotid arteries and the internal jugular veins with flexible tubing, flushed them to remove blood clots, and injected $50 \mathrm{~mL}$ of a polymethyl siloxane/silicone conglomerate (in 2:1 preparation) dyed with red water soluble pigment and another $50 \mathrm{ml}$ of this solution with blue water soluble pigment for each head. Specimens were refrigerated overnight and preserved in 200-proof ethyl alcohol diluted in water to a $70 \%$ solution. Subsequently, we performed a computed tomography (CT) scan of these heads to utilize the Neuronavigation System (Stryker, Kalamazoo, Michigan, USA). Then, we performed the expanded endonasal transtuberculum / transplanum approach.

\section{Anatomical Dissection}

The authors performed endoscopic anatomical dissections utilizing rod lens endoscopes (Karl Storz, $4 \mathrm{~mm}, 18 \mathrm{~cm}$, zero and $45^{\circ}$, Hopkins II; Karl Storz, Tutlingen, Germany) attached to a full high definition camera-HD (Karl Storz). They utilized the surgical technique previously described. ${ }^{1}$ The heads were placed in a 3-pin head holder positioned with the neck slightly extended and slightly turned to the right. The first step was the nasal phase. We performed a resection of the right middle turbinate, lateralizing the left middle turbinate. After this, we made a nasoseptal flap pedicled on the posterior septal artery. This flap was used for reconstruction of the skull base defect at the end of the procedure. A posterior nasal septectomy in addition to wide bi- lateral sphenoidotomies and posterior ethmoidectomies completed the nasal corridor. This maneuver facilitates working with four hands and, consequently, creates more space to use surgical tools (-Fig. 1).

We performed an anatomical and radiological correlation to the tuberculum sella to the medial optic-carotid recess (OCR), and the planum esphenoidale position were confirmed by the Neuronavigator System (Stryker, Kalamazoo, MI, USA). We drilled the bone of the tuberculum sellae, medial OCR bilaterally (the keyhole in this approach), the floor of sella, and of the planum sphenoidale until the posterior ethmoid arteries were reached utilizing a 3- or 4-mm hybrid cutting drill bit (Stryker, Kalamazoo, MI, USA). After we exposed the dura-mater, we opened it inferiorly from the distal dural ring to the contralateral distal dural ring, and superiorly from the dural roof of the optic canal (falciform ligament) to the contralateral optic canal. This extension of the dural opening allowed for direct access to the medial opticcarotid cistern. Then, we performed a careful dissection of the infrachiasmatic suprasellar space without pituitary transposition (-Fig. 2).

\section{Operative Technique}

The patient is placed on the table under general anesthesia. We routinely prescribe Cefuroxim (1.5 g) as prophylactic antibiotic. The head is fixed by a 3-point Mayfield head holder. We typically position the endotracheal tube on the patient's left side, allowing both surgeons access to the patient's face from the right. The patient's head is slightly rotated toward the right, so that the patient's face is pointing toward the surgeon standing on the right side. Finally, it is elevated above the heart to facilitate venous drainage. The patient's thigh is routinely prepared to get the autologous fascia lata and fat for reconstruction. The table is positioned in the reverse Trendlemburg to reduce the venous bleeding on the operating field. The face is cleaned with a topic chlorhexidine. Then, we perform the image guidance registration to facilitate the bone exposition during the whole procedure. We usually request the anesthesiologist team to keep the BPM (blood pressure medium) around $70-80 \mathrm{~mm} \mathrm{Hg}$. In this kind of approach, we place a lumbar drain in the patient and kept it in for 48 hours after surgery. The nasal phase begins by placing cottonoids soaked in epinephrine mixed with saline solution (1:4 solution) inside both nasal cavities using a zero degree endoscope (Storz, Germany, $18 \mathrm{~cm}$ $\times 4 \mathrm{~mm}$ ). After 10 minutes, we removed them and started the surgery.

The first surgical step is to remove right middle turbinate utilizing an endonasal scissors, increasing the posterior ethmoid and the ethmoidal- sphenoidal recess view. This maneuver should be done carefully, avoiding breaking the vertical attachment of the middle turbinate to the cribiform plate. The next step is to identify the space between the right sphenoid ostium and rhinopharinx vault to have a clear view of the pedicled nasalseptal flap, which is supplied by the posterior nasal septal artery. Care should be taken while enlarging the sphenoid sinus inferiorly to prevent injury to the vascular pedicle of the flap, which courses just inferior to the sphenoid sinus ostium. The flap confection is performed by the first cut at the bottom from the rhinopharinx vault, following the 


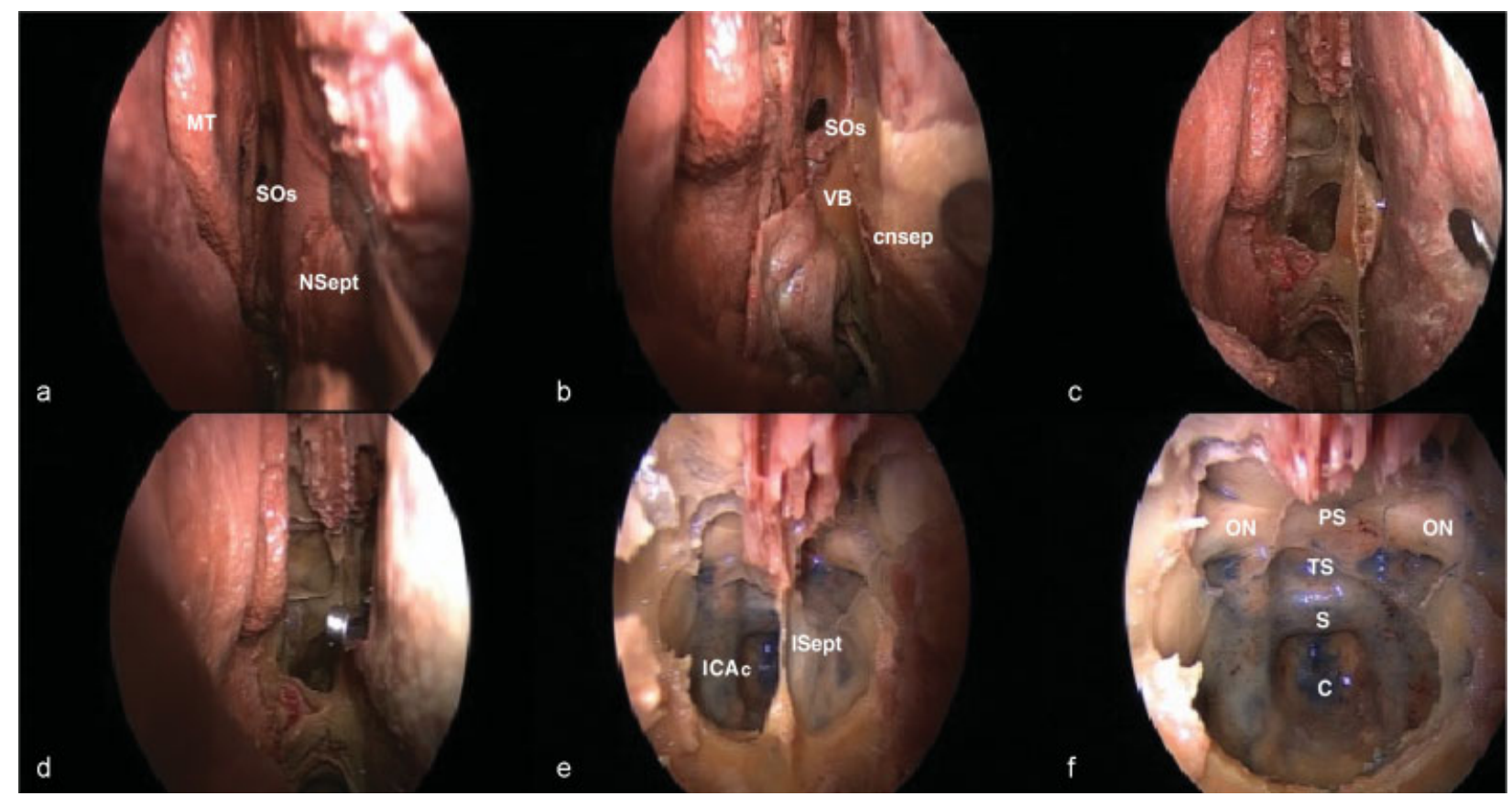

Fig. 1 These pictures [a] We are showing an overview of the nasal cavity with the exposition of the right middle turbinate (MT), nasal septum (NSept), and at the sphenoidale ostium (SOs). [b] After nasoseptal flap confection, the vomer bone (VB), the sphenoidale ostium (SOs), and contralateral nasoseptum (cnsep) are exposed. [c] Partial sphenoidectomy is completed. [d] A posterior septectomy is performed utilizing backbitter surgical tool. [e] A wide posterior ethmoidectomy is completed showing intrasphenoidale septum (ISept) going toward the left paraclival segment of the internal carotid artery (ICAC). [f] These pictures are showing wide exposition of the clivus (C), the planum sphenoidale (PS), the sella (S), the tuberculum sella (TS), and the optic nerves (ON).

hard plate, until $1 \mathrm{~cm}$ from the nasal vestibulum. The second cut is made under the sphenoid ostium keeping $1 \mathrm{~cm}$ away from posterior nasal olfactory strip. At the level of the middle turbinate axila, we continue to cut going up to near the cribiform plate until $1 \mathrm{~cm}$ from the nasal vestibule. The final cut is made at the anterior part of septal area connecting the previous two cuts. These cuts were performed utilizing an extended monopolar tip.

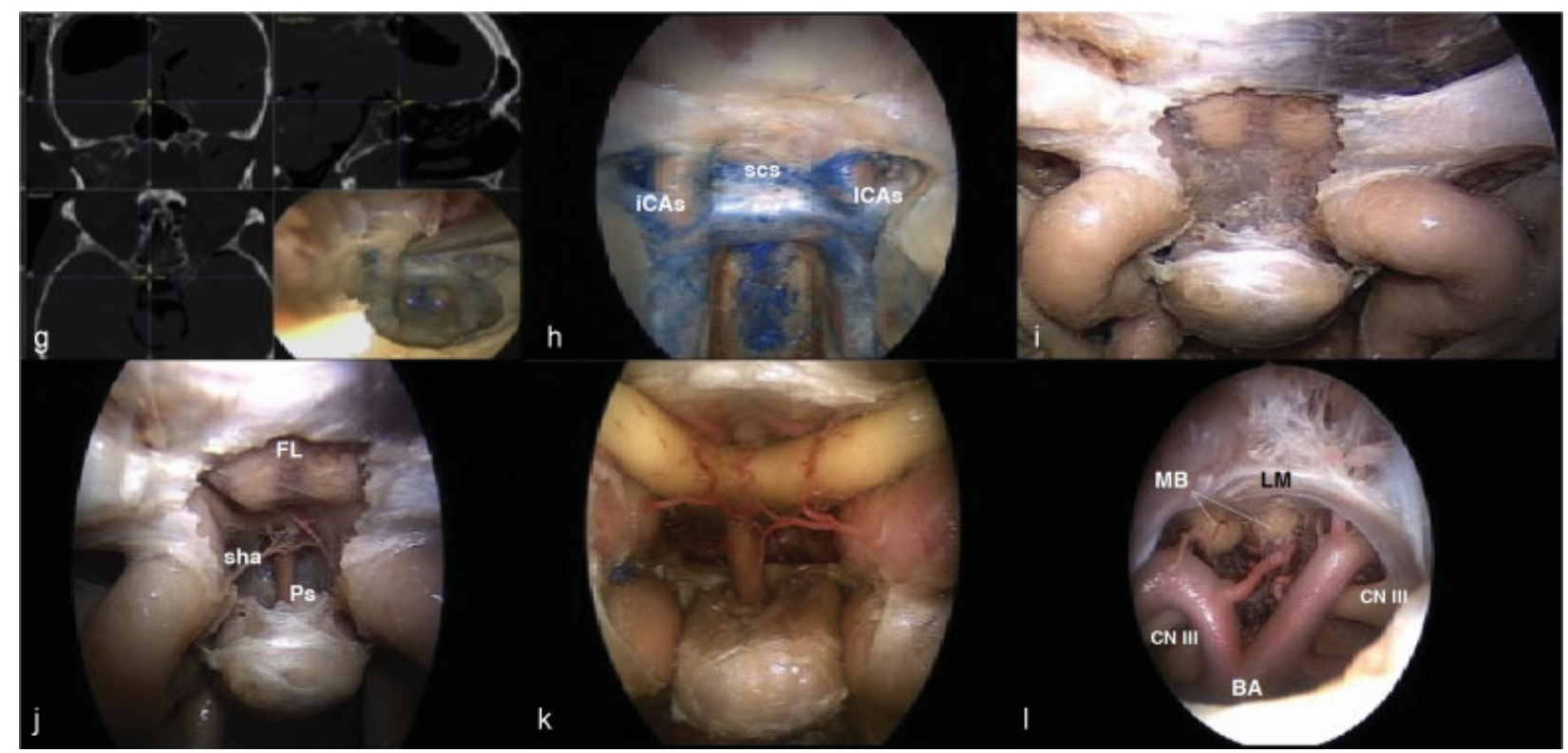

Fig. 2 [g] The middle OCR position was checked utilizing image guidance system, (mOCR is considered a keyhole for this access). [h] We expose both of the parasellar segment of the internal carotid artery (ICAs), and take the planum sphenoidale, the tuberculum sellae bone out to expose superior cavernous sinus (scs) and the dura-mater membrane. [i] We open the dura-mater membrane in $\mathrm{H}$-form exposing an infrachiasmatic arachnoid cistern. [j] After opening the arachnoid membrane, we find the frontal lobe (FL), the superior hypophyseal arteries (sha), and the pituitary stalk (Ps). [k] A complete overview of the infrachiasmatic suprasellar area. [I] A view of the retrochiasmatic area showing the concave Liliequist membrane (LM) attached in the third cranial nerves (CN III), the mamilary bodies (MB), and basilar apex (BA). 
Then the mucosa with muco-perichondrium and mucoperiosteum are lifted off, folded back, protected, and stored in the choana utilizing a cottle instrument and/or suction-dissector. These steps are crucial for posterior skull base reconstruction, thereby reducing CSF leak rates. The vomer bone is exposed after contralateral mucosa lateralization. Utilizing a back-bitter instrument, the posterior septectomy (around $2 \mathrm{~cm}$ ) is completed allowing a four-hand, two-nostril technique accomplishment. We need to preserve at least $1.5 \mathrm{~cm}$ of the anterior septal cartilage obviating an odd saddle nose complication.

After this step, the ENT and neurosurgeon work together. The former holds a zero-degree endoscope at 12 o'clock on the right nostril, the latter utilizing suction at 6 o'clock at the same nostril and another surgical instrument in both nostrils. A posterior ethmoidectomy may be done utilizing shaver laminae and/or trough-cut forceps, facilitating a lateral sphenoid sinus view. Using a 3-4 mm cutting drill bit with a high-speed drill, a wide sphenoidectomy is achieved. The vomer bone should be scraped down, allowing the work on the transplanum-transtuberculum area in caudal- cephalic angle utilizing zero degree scope. It is mandatory to round all of the bone edges obviating a difficult mucosa healing process during the postoperative time. In this step the image-guidance assistance facilitates the inter-sphenoid septum identification in the less pneumatized sphenoid sinus and the vital structures, which could be distorted by the tumor's presence. The sinus mucosa is taken out; this maneuver improves sella, planum, and tuberculum visualization, increasing the nasoseptal flap adherence to the bone in the skull base reconstruction phase. In this step, a 3-4 mm diamond burr is utilized after the image guidance check of the MOCR, the carotid arteries position, and the sphenoid planum. The bone over the sella, tuberculum, and planum sphenoidale is drilled with copious saline irrigation until an eggshell bone surface could be seen, facilitating a complete bone resection utilizing 1-2 mm kerrinson rongeurs.

The carotid arteries course is checked using a microdoppler. In this step, venous bleeding could arise from superior intercavernous sinus. Sometimes, it is quite difficult to achieve bleeding control. First, we elevate the head's position, utilize surgicel with gentle pressure, packing the intercavernous sinus with hemostatic agents such as Floseal or perform a complete coagulation of this superior sinus with Kassam and/or extended bipolar. The next step is to open the dura in the $\mathrm{H}$-form fashion, maximizing the optic nerves exposition and the carotid arteries view. The microsurgical phase is completed utilizing the same principles of the open standard microsurgical techniques. The presence of residual tumors is verified using a forty-five degree endoscope. The reconstruction phase is based on multilayer reconstruction technique (fascia lata inlay, fat, surgicel, fascia lata overlay, nasoseptal flap covering the whole defect, surgicel at the flap borders plus DuraSeal or other fibrin glue). After complete reconstruction, a final hemostasis is checked and we routinely do not use nasal splints.

\section{Illustrative Case}

A 63-year-old woman presented to our evaluation, complaining of visual loss in the left eye and a headache in the last six months. Upon physical examination, we noted bilateral temporal hemianopia without further neurological deficits. Her head computerized tomography (CT) scan showed a midline supra sellar lesion, with homogeneous contrast enhancement associated with a periostotic reaction at the tuberculum sellae. A sellar magnet resonance image (MRI) scan was performed ( - Fig. 3 ), in which we observed a lesion suggesting a Tuberculum sellae meningioma $(2 \times 2.2 \times 1$ $\mathrm{cm}$ ) without vascular encasement, and optic canal invasion, showing compression of the optic chiasm.

After multidisciplinary discussion, the authors decided to perform an EEETT approach, following the same principles of the microsurgical resection. The head was fixed in the Mayfield head holder, tilted toward the left shoulder and turned 20 to 30 degrees toward the right, with 15 degree extension. The endotracheal tube was positioned at the left side of the mouth, with the anesthesiologist and anesthesia equipment positioned on the patient's left side. A nasoseptal flap was raised. We performed a wide posterior ethmoidectomysphenoidectomy utilizing 3-4 $\mathrm{mm}$ burr. We checked the carotid arteries position utilizing a bayonet Microddopler (10-MHz ES-100X MiniDop with NRP-10H bayonet probe; Koven, St. Louis, Missouri, United States). The earlier dural coagulation (devascularization) facilitates the tumor's debulking from the posterior optic apparatus and the pituitary stalk ( - Fig. 4). The authors performed a complete resection. The skull base reconstruction was supported by a multilayer closure (fascia lata inlay and overlay, surgicel, nasoseptal flap, surgicel and fibrin glue, respectively). We placed a lumbar drainage for 48 hours after the procedure due to high flow of CSF leak found in this procedure. A postoperative sellar magnetic resonance imaging (MRI) scan showed a complete tumor resection. The patient was discharged from the hospital on the third postoperative day without any further neurological new deficits, presenting an improvement of her global vision, and without CSF leak. After six months, her MRI scan revealed no recurrence, and residual tumor. Her nose function completely improved three months after surgery.

The video is available at https://www.youtube.com/ watch?v=pnQ13_bcYh8.

\section{Discussion}

Since Yasargil has popularized microneurosurgery, ${ }^{6}$ open approaches have become the gold standard for surgical procedures to reach lesions located in the suprasellar and supra-infrachiasmatic area. ${ }^{7,8}$ This kind of approach is very suitable for lesions harbored in the midline, with lateral extension and vascular encasement as some tuberculum sella meningiomas, ${ }^{9,10}$ craniopharyngiomas, ${ }^{11}$ and giant pituitary tumors. ${ }^{12}$ Nonetheless, when utilizing this approach we should consider some drawbacks in comparison with the EEETT approach, such as a brain retraction, optic nerve 


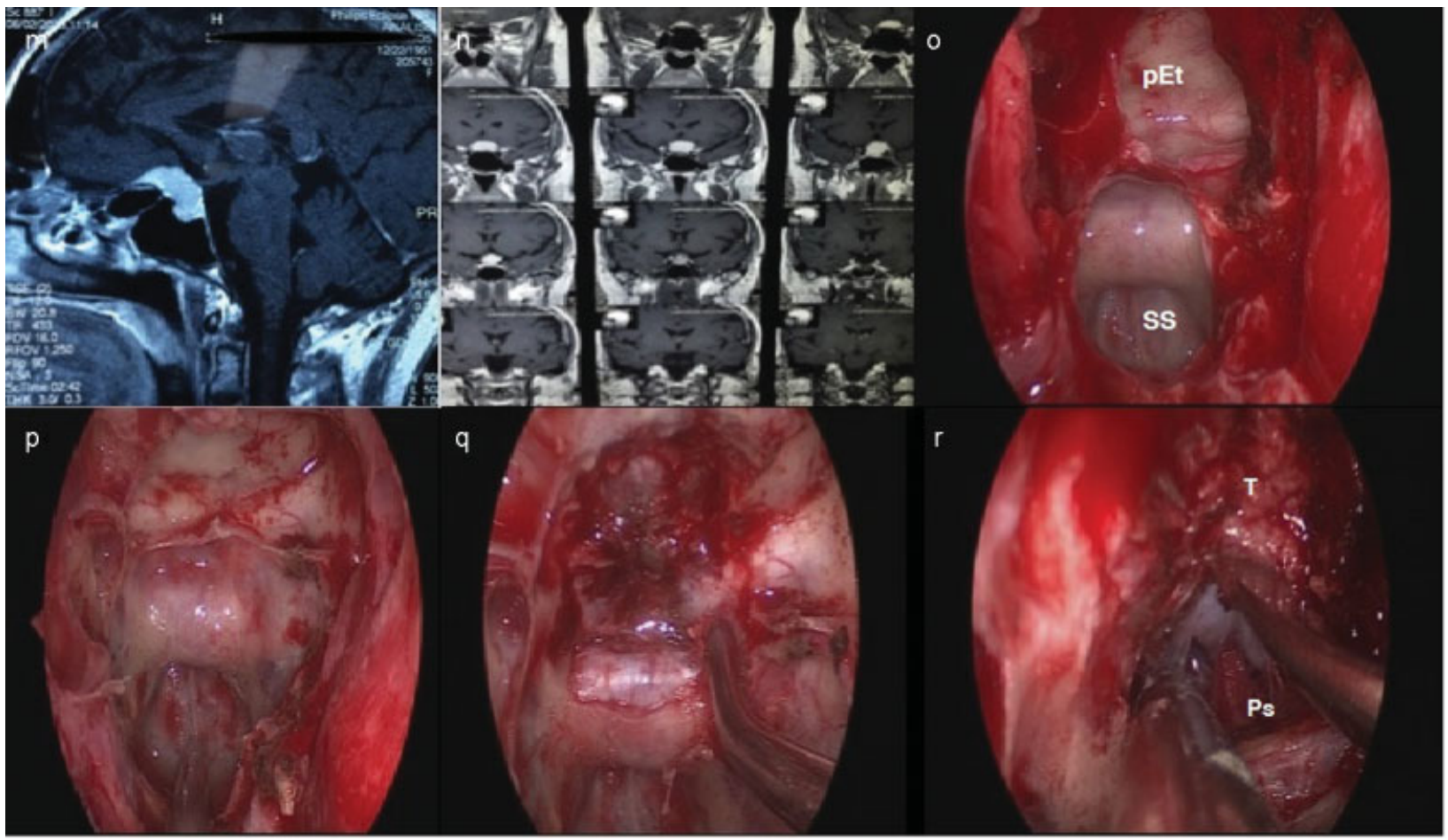

Fig. 3 [m] Sellar MRI scan on sagittal view showing a tuberculum sellae lesion with homogeneous contrast enhancement suggesting a tuberculum sella meningioma. [n] On the coronal view, we see a medial optic canal invasion with optic nerves compression. [o] After the initial rostrum sphenoidale drilling, the exposition of posterior ethmoid (pEt) and sphenoid sinus (SS) was completed. [p] An overview of the target area after the complete drilling of the posterior ethmoid and sphenoid sinus. [q] Following the removal of the planum sphenoidale, tuberculum sellae from mOCR to mOCR, partial bone removal over the sella, a micro-doppler was utilized to verify the carotid arteries course. [r] Before initiating the tumor resection, the pituitary stalk (Ps) was visualized after pushing the tumor (T) up, preserving the arachnoid plan.

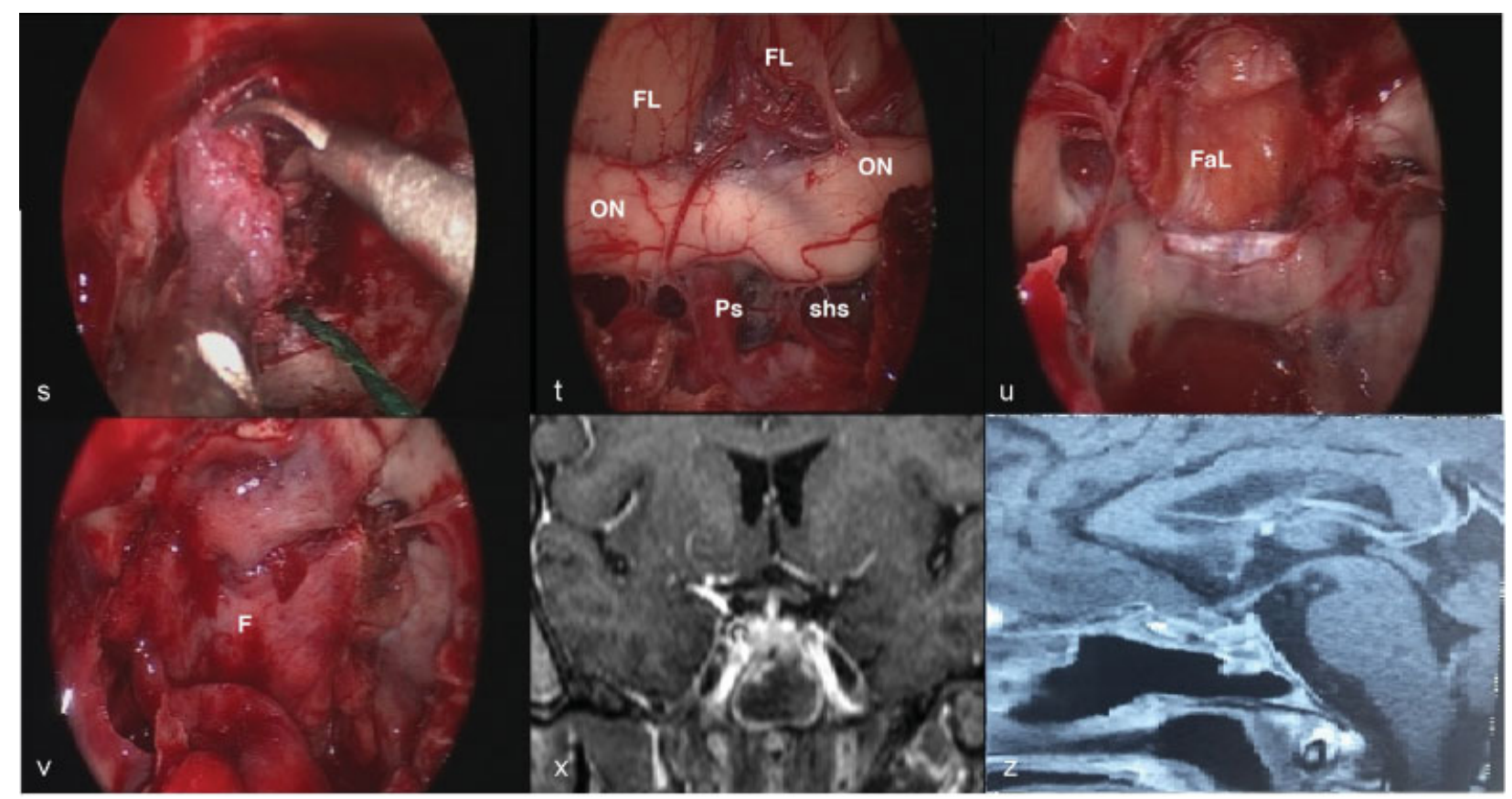

Fig. 4 [s] Utilizing customized endoscopic micro scissors, the tumor was removed in piecemeal fashion. [t] A complete removal of the tumor was achieved, visualizing the frontal lobes (FL), optic nerves (ON), pituitary stalk (Ps), and the superior hypophyseal arteries (sha). [u] Initiating the closure putting an inlay and overlay fascia lata (FaL), covering the whole bone defect following the principles of multilayer closure. [v] Haddad flap $(F)$ is covering the bone defect in total, being very important for the healing process to occur, obviating a CSF leak. [x] [z] Postoperative MRI scan on coronal and sagittal view showing a complete tumor removal. 
manipulation, and postoperative seizure development ranging from $15-20 \%{ }^{13}$ On the other hand, the EEETT approach is limited by the following: laterally by the carotid arteries, difficult hemostasis, the tumor's vascular involvement, 2-D endoscope visualization, and pre-fixed optic chiasm. Therefore, in the context of the minimally invasive approach, ${ }^{14}$ the EEETT development brought forth a safe surgical option to maximize midline lesions resection and minimizing the drawbacks of the open approaches. Thereby, it is possible to find an earlier tumor devascularization, a minimal optic apparatus manipulation, and a direct view of the anatomical structures presented in suprasellar infrachiasmatic area such as the optic nerves, the superior hypophyseal arteries, the pituitary stalk, and retrochiasmatic region.

Moreover, the ENT and neurosurgeon team collaboration dealing with the skull base pathologies enhances the endoscopic endonasal surgery success, minimizing postoperative nasal complications. ${ }^{15}$ Starting in the nasal phase after the pedicled nasoseptal flap development by Haddad, we obseved a striking decrease of CSF leak rates in the last years series for expanded endonasal approaches series ranging from $14.6 \%$ to $4 \%,{ }^{16} 58 \%$ to $23.4 \%{ }^{17}$ for craniopharyngiomas. The real value of the lumbar drainage to decrease the CSF leak rates after expanded surgeries may be questionable; therefore, no one prospective randomized study was able to answer this question. Success in targets exposition is directly tied with a wide sphenoid-posterior ethmoidectomy, maximizing the bone landmarks view, as mOCR, planum sphenoidale, and tubercullum sellae. In this context, the right middle turbinectomy may be questionable due to a nasal morbidity associated with it, such as anosmia and atrophic rhinitis. Nonetheless, a recent prospective cohort ${ }^{18}$ did not find out any difference related to quality of life (QoL) between patients that had undergone a bilateral middle turbinate resection and patients that had them preserved. For this surgical access, it is crucial to utilize an image guidance system and a microdoppler probe ${ }^{19}$ to achieve safe exposition of both medial optic-carotid recesses (mOCR), which is considered a keyhole for this access. An image-guidance system helps to minimize the planum sphenoidale bone resection and facilitates the skull base reconstruction. A zero-degree endoscope is a suitable instrument to guide the whole procedure to accomplish the four hands-two nostril technique. A forty-five degree endoscope has its utility to facilitate a visualization of the lesions that grow toward the third ventricle and laterally. One of the main advantages of this technique is not to cross the nerves as stressed by Kassam et al, ${ }^{20}$ facilitating a direct way to the retrochiasmatic area. This is considered a difficult access area for any chosen approach, due to the morbidity associated with lesions located in the hypothalamic area. Recent meta-analysis series for tuberculum sellae meningioma ${ }^{21}$ showed a rate of gross total resection in the EEA group of $60-92 \%$, whereas the transcranial rate was $74-92 \%$. EEA was not associated with a difference in rate of gross total resection compared with transcranial approaches ( $p>0.05$; OR 1.0; 95\% CI 0.86, 1.14). EEA was associated with an $11-43 \%$ complication rate compared with $5-28 \%$ in the transcranial group. Statistically, there was no difference in overall perioperative complications between the EEA and transcranial groups ( $p>0.05$; OR 1.1; $95 \% \mathrm{CI} 0.30,2.3$ ). The same study reported a $50-100 \%$ rate of visual improvement in EEA groups compared with 25-78\% in transcranial groups ( $p<0.05$; OR 1.5; 95\% CI 1.18-1.82). EEA were associated with significantly higher rates of postoperative visual improvement compared with transcranial approaches. Another EEETT complication of which the patient should be informed beforehand is a nasal morbidity (crusts, synechias, rhinosynusitis, nasal discharge, and stinky nasal odor). These kinds of complications usually take 3-6 months to achieve good improvement in the nasal quality of life. ${ }^{22,23}$

In this context, the EEETT approach should be considered as an option in dealing with midline lesions without vascular encasement. Even, if we always need to trade-off the risks and benefits of this approach versus traditional open approaches.

\section{Conclusion}

The EEETT is an amenable and minimally invasive option to the midline suprasellar lesions without vascular encasement and superior optic nerve involvement. The recent endoscopic advancements need more time follow-up and well-designed studies to compare the surgical results in relation to the traditional and well established open approaches to the suprasellar infra-chiasmatic area.

\section{References}

1 Kassam A, Snyderman CH, Mintz A, Gardner P, Carrau RL. Expanded endonasal approach: the rostrocaudal axis. Part I. Crista galli to the sella turcica. Neurosurg Focus 2005;19(1):E3

2 Schwartz TH, Anand VK. The endoscopic endonasal transsphenoidal approach to the suprasellar cistern. Clin Neurosurg 2007; 54:226-235

3 Cavallo LM, de Divitiis O, Aydin S, et al. Extended endoscopic endonasal transsphenoidal approach to the suprasellar area: anatomic considerations-part 1. Neurosurgery 2007;61(3, Suppl)24-33, discussion 33-34

4 Gardner PA, Kassam AB, Thomas A, et al. Endoscopic endonasal resection of anterior cranial base meningiomas. Neurosurgery 2008;63(1):36-52, discussion 52-54

5 Hadad G, Bassagasteguy L, Carrau RL, et al. A novel reconstructive technique after endoscopic expanded endonasal approaches: vascular pedicle nasoseptal flap. Laryngoscope 2006;116(10): 1882-1886

6 Yaşargil MG. Intracranial microsurgery. Clin Neurosurg 1970; 17:250-256

7 Gerganov V, Metwali H, Samii A, Fahlbusch R, Samii M. Microsurgical resection of extensive craniopharyngiomas using a frontolateral approach: operative technique and outcome. J Neurosurg 2014;120(2):559-570

8 Landeiro JA, Gonçalves MB, Guimarães RD, et al. Tuberculum sellae meningiomas: surgical considerations. Arq Neuropsiquiatr 2010;68(3):424-429

9 Mahamoud M, Nader R, Al-Mefty O. Optical canal involvement in tuberculum sellae meningiomas: influence on approach, recurrence and visual recovery. Neurosurgery 2010;67(3, Suppl Operative):ons108-ons118, discussion ons118-119 
10 Fernandes YB, Maitrot D, Kehrli P, Tella OI Jr, Ramina R, Borges G. Supraorbital eyebrow approach to skull base lesions. Arq Neuropsiquiatr 2002;60(2-A):246-250

11 Samii M, Bini W. Surgical treatment of craniopharyngiomas. Zentralbl Neurochir 1991;52(1):17-23

12 Buchfelder M, Kreutzer J. Transcranial surgery for pituitary adenomas. Pituitary 2008;11(4):375-384

13 Foy PM, Copeland GP, Shaw MDM. The incidence of postoperative seizures. Acta Neurochir (Wien) 1981;55(3-4):253-264

14 Louis RG, Eisenberg A, Barkhoudarian G, Griffiths C, Kelly DF. Evolution of minimally invasive approaches to the sella and parasellar region. Int Arch Otorhinolaryngol 2014;18(Suppl 2): S136-S148

15 Jho HD, Carrau RL. Endoscopic endonasal transsphenoidal surgery: experience with 50 patients. J Neurosurg 1997;87(1):44-51

16 Cavallo LM, Frank G, Cappabianca P, et al. The endoscopic endonasal approach for the management of craniopharyngiomas: a series of 103 patients. J Neurosurg 2014;121(1):100-113

17 Koutourousiou M, Gardner PA, Fernandez-Miranda JC, Tyler-Kabara EC, Wang EW, Snyderman CH. Endoscopic endonasal surgery for craniopharyngiomas: surgical outcome in 64 patients. J Neurosurg 2013;119(5):1194-1207

18 Soler ZM, Hwang PH, Mace J, Smith TL. Outcomes after middle turbinate resection: revisiting a controversial topic. Laryngoscope 2010;120(4):832-837

19 Dusick JR, Esposito F, Malkasian D, Kelly DF. Avoidance of carotid artery injuries in transsphenoidal surgery with the Doppler probe and micro-hook blades. Neurosurgery 2007;60(4, Suppl 2): 322-328, discussion 328-329

20 Kassam AB, Prevedello DM, Carrau RL, et al. Endoscopic endonasal skull base surgery: analysis of complications in the authors' initial 800 patients. J Neurosurg 2011;114(6):1544-1568

21 Clark AJ, Jahangiri A, Garcia RM, et al. Endoscopic surgery for tuberculum sellae meningiomas: a systematic review and metaanalysis. Neurosurg Rev 2013;36(3):349-359

22 de Almeida JR, Snyderman CH, Gardner PA, Carrau RL, Vescan AD. Nasal morbidity following endoscopic skull base surgery: a prospective cohort study. Head Neck 2011;33(4):547-551

23 Pant H, Bhatki AM, Snyderman CH, et al. Quality of life following endonasal skull base surgery. Skull Base 2010;20(1):35-40 